must lose their energy again in the photosphere and chromosphere, and in so doing will excite Röntgen radiation, both continuous, scattered and characteristic. The emission need not be confined to sunspots : Bartels' $M$-regions show that important solar phenomena can still remain undetected by us.

The mass-absorption coefficient $(\mu / \rho)$ of ultra-violet light is too great for this to penetrate to $100 \mathrm{~km}$. height. Too little is yet known about the value of $\mu / \rho$ for light between the ultra-violet and the Röntgen region ; systematic measures using the Hopfield continuous spectrum of helium are very desirable. For ultra-soft Röntgen radiation, the course of the $\mu / 0$ curve is known approximately to $\lambda=68 \mathrm{~A}$., for which wave-length Messner recently found $\mu / p=1.46 \times 10^{4}$. At $700 \mathrm{~A} ., \mu / \mathrm{p}$ is certainly much greater, probably similar to that of celluloids, for which O'Bryan found a maximum for $\mu / \rho\left(5.8 \times 10^{5}\right)$ at $800 \mathrm{~A}$. Probably Hulburt's estimate $\left(\mu / \rho \geqslant 8.8 \times 10^{5}\right)$ of $\mu / \rho$ for ultra-violet ionising light is truer than that used by Försterling $\left(1.2 \times 10^{5}\right)$.

The height of maximum ionisation depends essentially on $u / p$. If $\mu / p=5.5 \times 10^{5}$ (ultra-violet light), the height at midday must exceed $130 \mathrm{~km}$. if the air temperature $T$ is $218^{\circ} \mathrm{K}$, and a lower value of $T$ has not been proposed. This assumes no diffusive separation of the separate gases : if this occurs, the height might be $4 \mathrm{~km}$. lower. It would exceed $200 \mathrm{~km}$. if the outer layers consist of atomic oxygen as suggested by Chapman. Again, the fact that the gases of the atmosphere have absorption bands in the ultra-violet implies that the thickness of the absorbing layer must much exceed that of the ionised layer (scarcely $30 \mathrm{~km}$.) Hence ultra-violet light is unlikely to be the ionising agent for the $E$ layer, unless its value of $\mu / \rho$ has been over-estimated a hundredfold.

We are thus led to conclude that the, agent is Röntgen radiation. According as $T$ is taken to be from $218^{\circ}$ to $323^{\circ} \mathrm{K}$. (and it cannot exceed $100^{\circ} \mathrm{C}$. in the $E$-layer), the Röntgen wave-length will lie between $13 \mathrm{~A}$. and $3.5 \mathrm{~A}$, and also, on account of the $K$ absorption limit of nitrogen at $31 \cdot 1 \mathrm{~A}$., from $40 \mathrm{~A}$. to $31 \cdot 1 \mathrm{~A}$. As regards the characteristic radiations that may be involved, we may note the $K$-radiations from Na (11) to $\mathrm{Ca}(20)$, the $L$-radiations of $\mathrm{Ca}$ and those from $\mathrm{Cu}(29)$ to $\mathrm{Sn}(50)$, and the $M$-radiation from $\mathrm{Ce}(58)$ to $\mathrm{U}(92)$. The soft series for the elements near iron can be of importance only if $T<218^{\circ} \mathrm{K}$.

Siemens u. Halske A.-G., W.W.M., Berlin-Siemensstadt.

\section{Eocene Beds of the Punjab Salt Range}

Mr. E. S. PrNFoxd and I have recently made a special examination, on behalf of the Attock Oil Company, of the Eocene beds of the Punjab Salt Range, with the view of determining their exact age. It will be remembered that opinions as to this have varied greatly in the past, some geologists referring them to the Laki, others to the Khirthar, while others again have shelved the question of their precise age by calling them "Hill" limestones or "Nummulitic beds", etc.

I have now found, on examining fossils collected from these Eocene beds by Mr. Pinfold, that the beds are actually divisible into two distinct portions, the lower one belonging to the Ranikot and the upper to the Laki. Having lately received permission from the Attock Oil Company to publish our results, Mr. Pinfold and I hope shortly to produce a paper in which the relevant field and palæontological evidence will be discussed in detail.

\section{Garscube Terrace, Edinburgh 12.} Jan. 16.

\section{M. Davies.}

\section{"The Horizons of Thought"}

I kNow that a reviewer's comments on a book, especially when published in an international journal, travel many leagues while an author's reply is getting into an envelope, but for all that I would ask you to allow me to comment on your reviewer's words (in NATuRE of October 20, 1934, p. 617) concerning my book, "The Horizons of Thought". I am surprised to read that there is a "peculiar method" employed in the book; the reviewer seems to imply that it is a superficial eclecticism, which of course no one could countenance. As a matter of fact, the quotations are used for illustration and application of principles previously worked out and published in preliminary form elsewhere, as indicated in the preface. The reviewer seems to complain because contexts are not stated; they are omitted for the sake of brevity, and also because I was interested not so much in contexts as in contacts and conflicts with the principles worked out. I was interested not so much in elaborating my perhaps "general and obvious", and perhaps even "more or less relevant" conclusions, as in showing how often in contemporary thought their principles are disregarded, with consequences all the way "from mathematics to ethics". Finally, I must disclaim the wish which the reviewer imputes to me, of solving problems which lie beyond the horizons. I think the primary task of philosophy is to work within the island-universe of the sciences (logical, mathematical, natural and social), and treat a great mass of traditional outlying questions non-com. mittally.

\section{Department of Philosophy, \\ University of Minnesota, Minneapolis, U.S.A. Dec. 5 .}

George P. Conger.

I AM interested in Prof. Conger's letter, and I understand his points clearly. To deal with them satisfactorily would, however, occupy more space than could reasonably be asked for in NATURE; and $I$ do not think a controversy on these subjects would serve any practical purpose.

\section{The Reviewer.}

\section{Symbols for Chromosome Numbers}

I AGREE with Miss Schafer ${ }^{1}$ that the use of a Greek letter for the basic chromosome number has serious disadvantages and should therefore be dropped. But I think a new symbol is necessary, to avoid the confusion which results from a resuscitation of $x$ for this purpose. This symbol tends to be overworked, presumably because every schoolboy begins his algebra with $x$ as the unknown quantity. In the result we have papers written on the effect of $\mathrm{X}$-rays on the $X$-chromosome. In this case, however, no confusion results, because the two uses of $X$ are so different. 